Revue d'histoire de l'Amérique française

ZRS REVUE D.HISTOIRE DE L'AMÉRIQUE FRANÇAISE

\title{
Les prisons au Canada sous le Régime français
}

\section{André Lachance}

Volume 19, numéro 4, mars 1966

URI : https://id.erudit.org/iderudit/302513ar

DOI : https://doi.org/10.7202/302513ar

Aller au sommaire du numéro

Éditeur(s)

Institut d'histoire de l'Amérique française

ISSN

0035-2357 (imprimé)

1492-1383 (numérique)

Découvrir la revue

Citer cet article

Lachance, A. (1966). Les prisons au Canada sous le Régime français. Revue d'histoire de l'Amérique française, 19(4), 561-565.

https://doi.org/10.7202/302513ar d'utilisation que vous pouvez consulter en ligne.

https://apropos.erudit.org/fr/usagers/politique-dutilisation/ 


\section{LES PRISONS AU CANADA SOUS LE REGIME FRANÇAIS}

En Nouvelle-France, la prison n'était pas comme aujourd'hui un lieu où les criminels allaient expier leurs crimes, mais plutôt un endroit où l'on pouvait en sûreté garder les inculpés en attendant qu'ils puissent subir leur procès ou recevoir leur châtiment. ${ }^{1}$

Or il semble que la sûreté des geôles au Canada était assez relative. À ce propos MM. de Beauharnois et Hocquart écrivaient au Ministre, le comte de Maurepas, le 15 octobre 1730:

Vous devez être informé Monseigneur, que les prisons royales étaient si peu sûres, que les criminels, avant leur condamnation, avaient trouvé le secret de couper leurs fers et de rompre les grilles, par la communication qu'ils avaient avec les personnes du dehors par le moyen d'une fenêtre à rez de chaussée qui donnait dans une cour fermée simplement de pieus $[\ldots]^{2}$.

Nous savons à ce sujet que Louis Henry dit Leparisien, détenu pour vol, la nuit, à l'Hôtel-Dieu de Québec en 1706, dans les prisons du Palais de l'intendance, aurait réussi à s'évader si le concierge des geôles du Palais, Genaple, n'avait pas ce soir-là fait sa ronde. En effet vers les neuf heures du soir, il trouva Henry "deffergé" et en train avec "la branche de ses fers" d'enlever "plusieurs grosses pierres de la muraille du fond" de son cachot, de sorte que deux heures plus tard, selon Genaple, il “"aurait pu parachever de percer la muraille et s'évader" ${ }^{3}$.

${ }^{1}$ André Morel, "La justice criminelle en Nouvelle-France", dans Cite Libre, XIV, no 53 (janvier 1963): 28.

2 MM. de Beauharnois et Hocquart au Ministre, 15 octobre 1730, Archives de la Province de Québec, Manuscrits relatifs à l'histoire de la Nouvelle-France, 3ème série, vol. $11(1730-31)$ : sans pagination. 287.

3 Jugements et délibérations du Conseil supérieur, V, 22 mars 1706: 
Mais si Louis Henri dit Leparisien n'eut pas la chance de s'échapper, d'autres détenus, par contre, réussirent à s'évader. Ce fut le cas entre autres de trois soldats convaincus d'avoir participé à une sédition au fort Niagara en 1730. En octobre 1730 , nous retrouvions les trois séditieux dans les cachots de la prison de Montréal où ils attendaient la venue, de Québec, du maitre des hautes œuvres qui devait les prendre incessamment. Or deux récollets, les frères Césarée et Carpentier, trouvaient cette peine trop sévère et décidèrent d'aider les trois militaires à s'évader. C'est pourquoi ils procurèrent, clandestinement, aux militaires séditieux des limes avec lesquelles ces derniers coupèrent leurs fers. Et vers huit heures du matin, le 18 octobre 1730 , un des criminels feignant d'être malade, la fille du geôlier accourut pour lui porter secours. ${ }^{4}$ Mais à peine avait-elle ouvert la porte du cachot que les trois criminels se jetèrent sur elle. ${ }^{5}$ Par la suite. ils "forcèrent la sentinelle qui les gardait" et s'évadèrent en sautant par-dessus les palissades de la cour de la prison. Les deux frères récollets les conduisirent ensuite en canot jusqu'à Québec. ${ }^{6}$

Cependant non seulement les prisons au Canada n'offraient aucune sûreté, mais encore elles étaient insalubres. À ce sujet le procureur général du roi déclarait, en 1686, que "les Cachots des prisons" de la ville de Québec sont à ce point incommodes par "l'extrême humidité qui s'exale des murs, et des mauvaises [maladies] qui s'y contractent [...] qu'il n'est pas possible que les prisonniers y puissent résister" ?. Et 45 ans plus tard, rien n'avait encore changé puisque MM. de Beauharnois et Hocquart tenaient les mêmes propos au ministre de la Marine, le comte de Maurepas:

4 MM. de Beauharnois et Hocquart au Ministre, 23 octobre 1730, Archives de la Province de Québec, Manuscrits relatifs à l'histoire de la Nouvelle-France, 3ème série, vol. 12: sans pagination.

5 M. Hocquart au Ministre, 21 et 23 octobre 1731, Archives de la Province de Québec, ibid.: sans pagination.

6 MM. de Beauharnois et Hocquart au Ministre, 28 octobre 1730, Archives de la Province de Québec, ibid.: sans pagination.

7 Jugements et délibérations du Conseil souverain, III, 3 septembre 1686: 71-72. 
[...] les cachots sont si malsains par l'humidité qui y règne qu'il n'est pas possible à des hommes d'y pouvoir séjourner continuellement $[\ldots]^{8}$.

En hiver les conditions étaient encore plus pénibles car les prisonniers devaient en plus combattre le froid, puisque les cachots n'étaient pas chauffés. Il fallut même quelquefois, comme l'écrivait $M$. de Denonville au ministre de la Marine, JeanBaptiste Colbert, le 8 mai 1686, couper les pieds de certains prisonniers parce que la gangrène les avait atteints. ${ }^{9}$ Ainsi donc les prisons de Québec ne valaient pas "grand chose".10

Et il en était de même des prisons de Montréal dont on ne pouvait plus se servir en 1699 , les pièces de bois de la prison "étant toutes pourries"."11

Heureusement quelquefois il y avait, pour les prisonniers qui vivaient dans ces lieux insalubres, des compensations; ainsi en fut-il de Jean Corolère. Jeune homme d'une vingtaine d'années, il était, au début de 1751, tambour de la compagnie des bombardiers et canonniers dans les troupes de la Marine, en garnison à Québec. ${ }^{12}$ Or voici que le 26 janvier, il se battit en duel avec un soldat nommé Coffre. La Justice du pays s'empressa d'arrêter les coupables et c'est pourquoi, dès le 30 janvier 1751, le lieutenant général de la prévôté de Québec commençait l'instruction dans la cause pour duel contre Jean Corolère. Mais le procès traîna en longueur, ${ }^{13}$ et ce n'est que le 2 juin 1751 que le Conseil supérieur de la Nouvelle-France le condamna à un an de prison. ${ }^{14}$

8 MM. de Beauharnois et Hocquart au Ministre, 15 octobre 1730, Archives de la Province de Québec, op. cit., vol. 11: sans pagination.

9 M. de Denonville au Ministre, 8 mai 1686, Archives de la Province de Québec, ibid., 2ème série, vol. 5: 237.

10 M. de Meulles au Ministre, 28 septembre 1686, ibid., 4: 270. 8: 412 .

11 MM. de Callières et Champigny au Ministre, 20 octobre 1699, ibid.,

12 Archives de la Province de Québec, Collection de pièces judiciaires et notariales, interrogatoire de Jean Corolère, 30 janvier 1751: dossier no 1646. 13 Loc. cit.

14 P.-G. Roy, Inventaire des jugements et délibérations du Conseil supérieur de la Nouvelle-France, II : 179. 
Mais de janvier à juin 1751, Corolère avait eu le temps de faire la connaissance de sa voisine de cellule, une certaine Françoise Laurent, domestique de 20 ans, originaire de Montréal. ${ }^{15}$ Fille du tambour-major de Montréal, Guillaume-Antoine Laurent, et de Marie-Charlotte Provençal ${ }^{16}$, elle attendait dans les prisons royales de Québec que l'on trouvât un exécuteur pour la pendre. ${ }^{17}$ L'ancien bourreau était mort le 28 décembre $1750 .{ }^{18}$ Le 12 mars 1751, Françoise Laurent avait été reconnue coupable d'avoir volé certains vêtements chez les Pomereau, où elle travaillait comme domestique. ${ }^{19}$ Avant de servir les Pomereau, elle avait été placée quelque temps à l'Hôpital Général de Montréal "parce qu'elle courais avec les hommes". ${ }^{20}$ Par conséquent cette fille savait comment s'y prendre avec le sexe fort et n'eut pas trop de difficultés à conquérir Corolère. Elle l'ensorcela si bien qu'après cinq mois de séjour en prison, il désirait l'épouser. Or la Laurent était une condamnée à mort et il n'y avait qu'un moyen pour Corolère de l'épouser et de la sauver en même temps de la potence: devenir exécuteur de la haute justice. C'est dans ce but que le 17 août 1751, il présenta au Conseil supérieur "un écrit" dans lequel il suppliait "la Cour de vouloir l'accepter pour exécuteur des hautes œuvres [...]".21 Après avoir délibéré, les conseillers acceptèrent sa demande et lui octroyèrent la place de maître des hautes œuvres en Canada. Par le fait même, ils le libérèrent aussi de l'obligation qu'il avait de tenir prison pendant encore une dizaine de mois..2 ${ }^{22}$ Mais dès le lendemain, il présentait une requête au Conseil supérieur où il déclarait que "voulant former un établissement solide" il suppliait "la Cour de vouloir lui accorder en mariage la nommée Françoise Laurent, fille, détenue

\footnotetext{
15 Archives de la Province de Québec, op. cit., interrogatoire de Françoise Laurent, 12 mars 1751: dossier no 1645.

16 Registre de Notre-Dame de Québec, 1748-1752, 19 août 1751: 218.

17 Roy, op. cit., II: 174.

18 Procès verbal du lieutenant général de la prévôté de Québec, François Daine, fait le 28 décembre 1750; et cité par P.-G. Roy dans Le vieux Québec, Première série: 205s.

19 Archives de la Province de Québec, op. cit.: dossier no 1645.

20 Loc. cit.

21 P.-G. Roy, op. cit., II: 180.

22 Loc. cit.
} 
aux prisons royaux de cette ville" ${ }^{23}$. Le Conseil, après délibérations, déchargea Françoise Laurent des condamnations prononcées contre elle le 12 mars 1751, à la condition qu'elle consentit à épouser Corolère. ${ }^{24}$ Le jour suivant, le 19 août 1751 , le vicaire de la paroisse Notre-Dame de Québec, l'abbé Lamicq, mariait dans la chapelle du Palais de l'intendance ${ }^{25}$ l'exécuteur Jean Corolère à la condamnée à mort, Françoise Laurent. ${ }^{26}$

Ainsi si on analyse un peu les événements des 17,18 et 19 août 1751, Françoise Laurent avait atteint son but: se sauver de la potence. Car, telle que nous la connaissons maintenant, nous pouvons certainement la soupçonner d'être à l'origine des deux “écrits" que Corolère présenta au Conseil, les 17 et 18 août 1751.

Ce n'est donc pas d'hier qu'on se plaint du mauvais état de nos prisons. Déjà sous le régime français les autorités du pays faisaient entendre leurs doléances. Mais les prisonniers d'alors possédaient un avantage sur ceux d'aujourd'hui, puisqu'ils pouvaient espérer, pour rendre leur séjour, dans ces lieux sinistres, moins sombre, avoir comme voisine de cellule une "gentille demoiselle"!

Collège de Lévis.

ANDRÉ LACHANCE,

L. ès L. (histoire).

23 Loc. cit.

24 Loc. cit.

25 P.-G. Roy, La ville de Québec sous le régime français, II: 224.

26 Registre de Notre-Dame de Québec, 1748-1752, 19 août 1751: 218. 